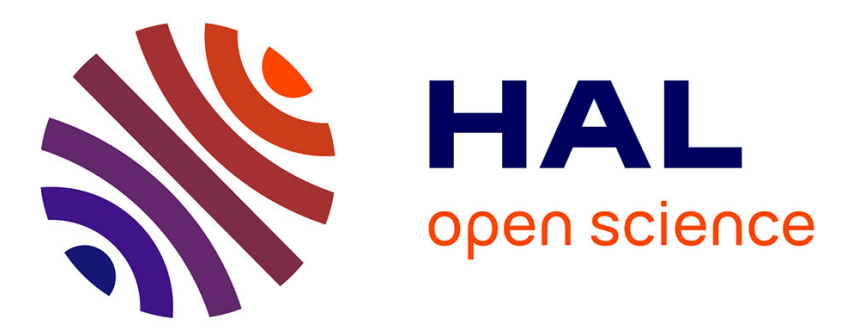

\title{
Polyethylene Aerogels with Combined Physical and Chemical Crosslinking: Improved Mechanical Resilience and Shape-Memory Properties
}

Douriya Khedaioui, Christophe Boisson, Franck d'Agosto, Damien Montarnal

\section{To cite this version:}

Douriya Khedaioui, Christophe Boisson, Franck d'Agosto, Damien Montarnal. Polyethylene Aerogels with Combined Physical and Chemical Crosslinking: Improved Mechanical Resilience and ShapeMemory Properties. Angewandte Chemie International Edition, 2019, 10.1002/anie.201908257 . hal02316550

\author{
HAL Id: hal-02316550 \\ https://hal.science/hal-02316550
}

Submitted on 12 Nov 2020

HAL is a multi-disciplinary open access archive for the deposit and dissemination of scientific research documents, whether they are published or not. The documents may come from teaching and research institutions in France or abroad, or from public or private research centers.
L'archive ouverte pluridisciplinaire HAL, est destinée au dépôt et à la diffusion de documents scientifiques de niveau recherche, publiés ou non, émanant des établissements d'enseignement et de recherche français ou étrangers, des laboratoires publics ou privés. 


\title{
Polyethylene aerogels combining physical and chemical crosslinking allow improved mechanical resilience and shape- memory properties.
}

\author{
Douriya Khedaioui, ${ }^{[a]}$ Christophe Boisson, ${ }^{[a]}$ Franck D'Agosto ${ }^{[a]}$ and Damien Montarnal[a]*
}

\begin{abstract}
While the introduction of polymers in aerogels strongly enhances their toughness, truly elastic monolithic aerogels able to restore their dimensions upon extensive compression are still challenging to synthesize. In this context hydrophobic semi-crystalline polymers with low glass transition temperatures that combine both stiffness and flexibility have only recently gained attention. We show that polyethylene aerogels with low density combining chemical crosslinking and high crystallinity display high moduli and excellent mechanical resilience. In order to maximize the crystallinity of these aerogels while maintaining a high crosslinking density, we synthesized polyethylene networks with well-defined segments by hydrosilylation-crosslinking of telechelic, vinyl-functionalized oligomers obtained from recent advances in catalyzed chain growth polymerization. Recoverable deformations both above and below the melting temperature of polyethylene affords remarkable shapememory properties.
\end{abstract}

\section{Introduction}

Porous materials comprising a hierarchical structuration of pores, with sub-micronic sizes and high surface areas currently find growing applications such as thermal and phonic insulators, super-absorbents, supports for catalysis and membranes for supercapacitors or batteries. ${ }^{[1]}$ Aerogels have been historically obtained through sol-gel polymerization of alkoxysilanes in diluted solutions, ${ }^{[1 \mathrm{~b}, 2]}$ although an extensive range of precursors has been used since then: metal oxides, ${ }^{[3]}$ graphene, ${ }^{[4]}$ but also thermosetting polymer resins ${ }^{[5]}$ and supramolecular assemblies. ${ }^{[6]}$ After gelation, the extraction of the solvent must be carried out by specific techniques that strongly reduce capillary stresses (e.g. supercritical drying with $s$ $\left.\mathrm{CO}_{2}\right){ }^{[7]}$ This is particularly important to prevent collapse of the pores if they are only a few nanometre large, or if the solid network is not rigid enough. Metal-organic and silane based precursors undergoing hydrolysis and condensation steps, such as tetraethoxysilane, ${ }^{[8]}$ form a network of nanometer-sized particles with extreme crosslinking densities and Young Moduli above $50 \mathrm{GPa}$, thus the resulting aerogels can reach surface areas up to $2000 \mathrm{~m}^{2} \mathrm{~g}^{-1}$ yet they

[a] Douriya Khedaioui, Dr. Christophe Boisson, Dr. Franck D’Agosto, Dr. Damien Montarnal*

Univ Lyon. Université Claude Bernard Lyon 1, CPE Lyon, CNRS UMR 5265, Chemistry, Catalysis, Polymers and Processes 43 Bvd du 11 Novembre 1918, F-69616 Villeurbanne, France E-mail: damien.montarnal@univ-lyon1.fr

Supporting information for this article is given via a link at the end of the document. are extremely brittle. In contrast, covalent organic aerogels formed by crosslinking small polyfunctional molecules in solution (e.g. resorcinol-formaldehyde ${ }^{[9]}$ or diisocyanate/tetra-ols ${ }^{[10]}$ ) form larger particles with glass transition temperatures above ambient, and have Young Moduli of about 1-2 GPa. Thus, they lead to aerogels with lower surface areas, in the range $10-500 \mathrm{~m}^{2} \mathrm{~g}^{-1}$, and with a tendency to comprise a larger and hierarchical distribution of pore sizes, typically mesopores in the 5-50 nm range, but also larger macropores over $50 \mathrm{~nm}$. Such organic aerogels are however much less brittle than inorganic aerogels, sometimes even flexible and can be handled much more easily. High performance, flexible aerogels have also been obtained by combining sol-gel chemistry and polymerization. ${ }^{[11]}$ Another class of organic aerogels is constituted by high molar mass semicrystalline polymers. Such materials are obtained from entangled dilute solutions that undergo physical gelation upon crystallization of polymer segments. A large variety of hydrophilic polymer-based aerogels, often derived from biomass, has been studied over the years. ${ }^{[11 c, 12]}$ Continuous progress driven lately by biocompatible applications of such aerogels as scaffolds for tissue engineering, regenerative medicine ${ }^{[13]}$ or drug delivery ${ }^{[14]}$ has led to a good understanding of the physical gelation occurring in such systems, driven by crystallizationinduced phase separation. Most of these aerogels are however very hygroscopic and if not properly hydrophobized, ${ }^{[15]}$ many of their physical properties (e.g. modulus, thermal conductivity) are dramatically altered upon water uptake. More recently, the seminal work of Guerra on the development of aerogels from hydrophobic semicrystalline polymers (e.g. syndiotactic-polystyrene, poly(vinylidene fluoride) or poly(4-methyl-pentene) $)^{[16]}$ opens a new paradigm for organic aerogels. Similarly to hydrophilicbased aerogels, high crystallinity compensates the absence of a densely crosslinked structure and prevents collapse of low-density, porous structures. In some cases, it has even been shown that certain polymers could undergo cocrystallization with the solvent, thus forming nanopores after removal of the guest solvent molecules. High density linear polyethylene (HDPE) displays numerous advantages in this scope: it is widely available, inexpensive, intrinsically hydrophobic, has an excellent chemical resistance, amongst the highest attainable crystallinities, and melting temperatures above $100^{\circ} \mathrm{C}$ compatible with many insulation requirements. HDPE foams, obtained by coextrusion of HDPE, optional crosslinkers and blowing agents, with closed cells ranging from 20 microns to several millimeters are 
extensively investigated and commercialized for packaging. ${ }^{[17]}$ In contrast, obtaining HDPE with open submicronic pores is much more challenging: HDPE membranes for battery separators with moderate porosity ca. $40 \mathrm{vol} \%$ are obtained from the melt by a succession of annealing and stretching steps (dry process), and also by adjunction of solvents to obtain smaller pores (wet process). ${ }^{[18]}$ The synthesis of low density, microporous aerogels from HDPE was only attempted by Mülhaupt and coworkers through templated synthesis of ethylene on PVA nanofibers, ${ }^{[19]}$ or by Guerra and coworkers who synthesized gels of ultrahigh molecular weight polyethylene (UHMWPE) in decalin by crystallization, and obtained aerogels by subsequent extraction with $s-\mathrm{CO}_{2} \cdot{ }^{[20]}$ These aerogels were however mainly constituted of large lamellae loosely bound together, with a majority of macropores. (> $500 \mathrm{~nm}$ ). Complementary experiments on similar materials described here demonstrate poor mechanical performances: low Young Moduli and extremely low resilience (e.g. almost no recovery of dimensions upon compressive deformation).

We propose here an innovative and versatile approach to improve the mechanical performances of aerogels of semicrystalline polymers by introducing chemical crosslinks that form densely crosslinked gels, but still maintain a high crystallinity of the polymer. This concept is demonstrated by producing high density polyethylene aerogels with excellent moduli and compression recovery. This unusual combination of high crystallinity with narrow melting transition, and dense covalent crosslinking gives rise to remarkable "shape memory" properties.

It has been shown previously on copolymers of ethylene that for a given degree of modification, random distribution of comonomers induces a broader melting range and an overall lower crystallinity than regularly spaced co-monomers. ${ }^{[21]} \mathrm{By}$ analogy, our strategy builds upon the synthesis of homogeneous polymer networks from well-defined, endfunctional and highly crystallizable segments crosslinked in diluted media (Figure 1). It is strongly tied to the developments of catalyzed chain growth polymerization that made possible the synthesis of telechelic and very linear HDPE oligomers, exhibiting low dispersity and a variety of reactive end-groups. ${ }^{[22]}$

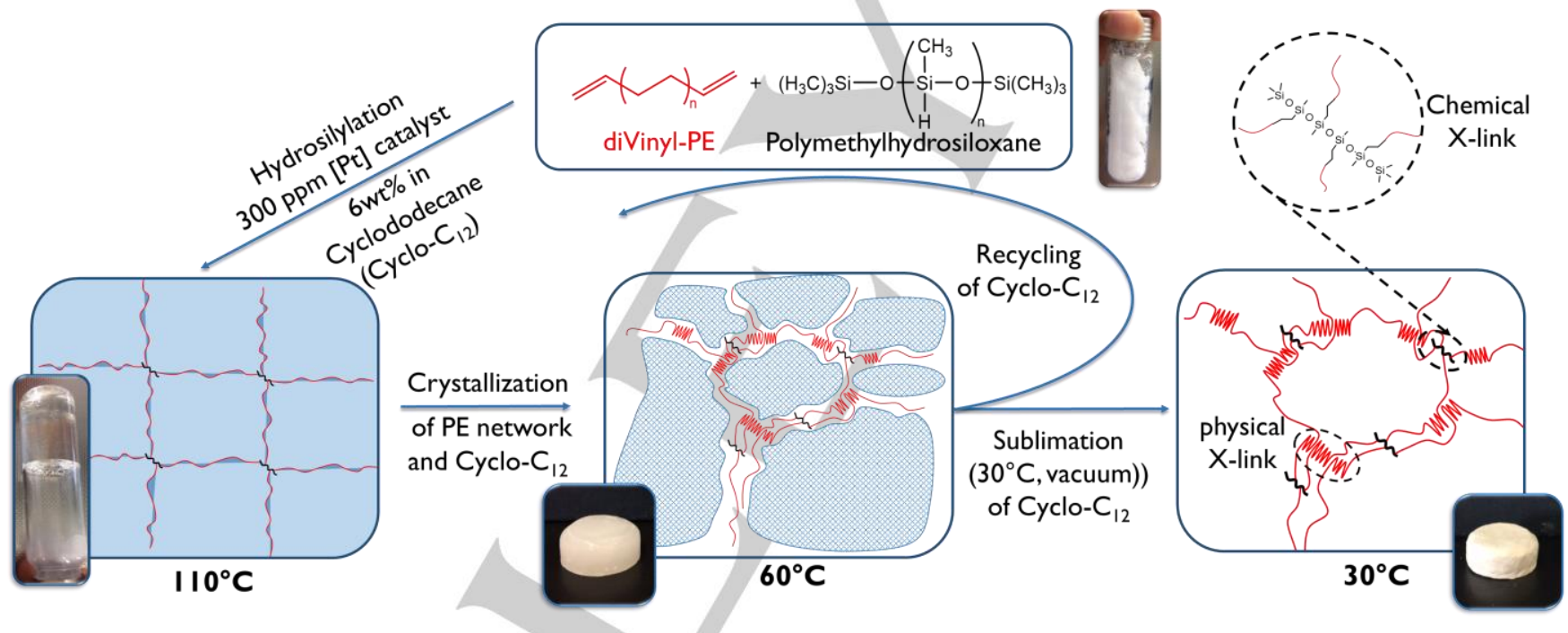

Figure 1. Elaboration of polyethylene-based aerogels by hydrosilylation of $\alpha, \omega$-divinyl-polyethylenes and polyhydrosilanes in cyclododecane.

\section{Results and Discussion Polyethylene synthesis}

The synthesis of divinyl-PE telechelic polymers was performed in two steps through an $\alpha, \omega$-vinyl-iodo $P E$ intermediate as previously described. ${ }^{[23]}$ A variety of polymers with low dispersity, high vinyl functionality and molar masses ranging between 600 and $2000 \mathrm{~g} \mathrm{~mol}^{-1}$ was obtained (Table 1).

\section{PE Gelation by platinum-catalyzed hydrosilylation reaction}

While such highly functional and crystalline polymers represent ideal building blocks for the synthesis of chemically crosslinked PE gels, homogeneous crosslinking in highly dilute solutions is a challenging task that imposes highly effective reactions. ${ }^{[24]}$ We turned thus to platinum-catalyzed hydrosilylation as a well-known, robust and efficient coupling reaction between a vinyl and a hydrosilane, also compatible with dilute and apolar media. While Karstedt's catalyst, i.e. $\mathrm{Pt}_{0}$ with divinyl tetramethyldisiloxane (dvtms) ligands, is ubiquitously used between hydrosilanes and vinyl silanes for its excellent activity, selectivity and robustness, it is also known to induce side reactions such as isomerization or hydrogenation that, in our case, would immediately reduce the crosslink density of the gels. ${ }^{[25]}$ Alternatives to Karstedt's catalyst with higher selectivity have been developed by Markó and coworkers by combining N-heterocyclic carbenes 
(NHC) and dvtms ligands. ${ }^{[26]}$ We thus focused on three catalysts with $\mathrm{NHC}$ bearing cyclohexyl: (NHC-Cy)Pt(dvtms), tertbutyl: (NHC-tBu)Pt(dvtms), and isopropyl: (NHCiPr)Pt(dvtms) substituents, respectively. The catalysts were either synthesized as previously described or bought from commercial suppliers, they were fully characterized with ${ }^{1} \mathrm{H}$, ${ }^{13} \mathrm{C}$ and ${ }^{195} \mathrm{Pt}$ NMR (Figure S1, S2, S3). A first model reaction of diluted solutions of 1-eicosene and polyhydrosilane oligomers in presence of catalyst enabled to confirm that
Karstedt's catalyst had a higher activity than $\mathrm{NHC}$ derivatives. In a first approach, the reaction was performed at $6 \mathrm{wt} \%$ in $\mathrm{CDCl}_{3}$. Yet, the final amount of isomerization and dehydrogenation, about $20 \mathrm{~mol} \%$ after $2 \mathrm{~h}$ at $110^{\circ} \mathrm{C}$, was similar for all catalysts. (Figures S4-S6). In-situ monitoring of gelation of the divinyl-PE / polyhydrosilane system in cyclododecane was carried out by rheology, using small amplitude oscillatory shear and a sealed cell with concentric cylinders (Figure 2).

\begin{tabular}{|c|c|c|c|c|c|c|c|c|c|c|c|c|}
\hline \multirow[b]{2}{*}{ Sample } & \multicolumn{7}{|c|}{ Polymers } & \multirow{2}{*}{$\begin{array}{c}\text { Gels } \\
\mathrm{G}_{\text {gel }}^{\prime}{ }^{[\mathrm{g}]} \\
(\mathrm{kPa})\end{array}$} & \multicolumn{4}{|c|}{ Aerogels } \\
\hline & $\begin{array}{c}M_{\mathrm{n}}^{[\mathrm{a}]} \\
\left(\mathrm{g} \mathrm{mol}^{-1}\right)\end{array}$ & $\Theta^{[a]}$ & $\begin{array}{l}\text { di-Vinyl } \\
\text { PE }(\%)^{b}\end{array}$ & $\begin{array}{c}{[n]^{[c]}} \\
\left(\mathrm{dL} \mathrm{g}^{-1}\right)\end{array}$ & $\begin{array}{c}\varphi^{*[d]} \\
(w t \%)\end{array}$ & $\begin{array}{l}\mathrm{T}_{\mathrm{m}}{ }^{[\mathrm{e}]} \\
\left({ }^{\circ} \mathrm{C}\right)\end{array}$ & $\begin{array}{l}X_{c}^{[f]} \\
(\%)\end{array}$ & & $\begin{array}{c}X_{\text {aeroge }}{ }^{[i]} \\
(\%)\end{array}$ & $\begin{array}{c}d_{\text {aeroge }} \mathrm{e}^{[j]} \\
\left(\mathrm{mg} \mathrm{cm}^{-3}\right)\end{array}$ & $\begin{array}{c}\text { Eaerogel }^{[\mathrm{k}]} \\
(\mathrm{kPa})\end{array}$ & $\begin{array}{l}\mathrm{T}_{\mathrm{m}}^{[l]} \\
\left({ }^{\circ} \mathrm{C}\right)\end{array}$ \\
\hline PE-600 & 620 & 1.2 & 95 & 0.019 & 53 & 71 & 69 & 0.21 & 37 & 74 & 93 & 60 \\
\hline PE-1000 & 1050 & 1.2 & 94 & 0.030 & 33 & 105 & 77 & 0.43 & 36 & 51 & 130 & 92 \\
\hline PE-1500 & 1450 & 1.2 & 93 & 0.038 & 27 & 114 & 81 & 1.7 & 43 & 83 & 150 & 102 \\
\hline PE-2000 & 1920 & 1.2 & 93 & 0.047 & 21 & 121 & 83 & 4.5 & 42 & 120 & 600 & 111 \\
\hline UHMWPE & $3-6.10^{6}$ & - & - & - & - & 132 & 39 & $1.4^{[\mathrm{h}]}$ & 73 & 110 & 18 & 134 \\
\hline
\end{tabular}

Table 1. [a-f]: Characterization of divinyl-PE telechelic polymers. [g-h]: Characterization of their gels in $\mathrm{CDD}\left(47 \mathrm{mg} \mathrm{cm}{ }^{-3}\right.$ of polymers, $\mathrm{SiH} / \mathrm{Vinyl}=2 / 1,300 \mathrm{ppm}$ of NHC-based catalyst). [i-l] Characterization of the aerogels after sublimation of CDD. [a] Determined by high-temperature SEC using PE calibration. [b] Determined by ${ }^{1} \mathrm{H}$ NMR. [c] Intrinsic viscosity in TCB at $150^{\circ} \mathrm{C}$ determined by high-temperature SEC using the differential viscometer. [d] Critical overlap polymer fraction estimated from the intrinsic viscosity using $\varphi^{*}=1 /[\eta]$. [e] Determined by DSC. [f] Crystallinity determined during the first heating by DSC from melting enthalpies using $\Delta \mathrm{H}_{\mathrm{m}}=293 \mathrm{J.g}^{-1}$ as reference. [g] Storage modulus of the $6 \mathrm{wt} \%$ gels in CDD, after crosslinking for $15 \mathrm{~h}$ at $110^{\circ} \mathrm{C}$. [h] Storage modulus after crystallization of UHWMPE at $70^{\circ} \mathrm{C}$. [i] Crystallinity of aerogels determined as in [f]. [j] Apparent densities of aerogels. [k] Compression modulus of aerogels. [l] Melting temperature of aerogels as in [e].

Karstedt's catalyst is too effective in such conditions, and the crosslinking occurred before the catalyst was properly mixed thus leading to inhomogeneous gels. Crosslinking PE-2000 with (NHC-Cy)Pt(dvtms), (NHC-tBu)Pt(dvtms) and (NHCiPr) $\mathrm{Pt}(\mathrm{dvtms})$ leads to gel times of $5 \mathrm{~h}, 45 \mathrm{~min}$ and $20 \mathrm{~min}$, respectively, which is fully consistent with the activities of the corresponding catalysts reported in Markó's work. The storage moduli after $15 \mathrm{~h}$ of reaction at $100^{\circ} \mathrm{C}$ are however very different, ranging from $0.7,1.9$ and $4.5 \mathrm{kPa}$, respectively. In this system, rheology is thus a tool that

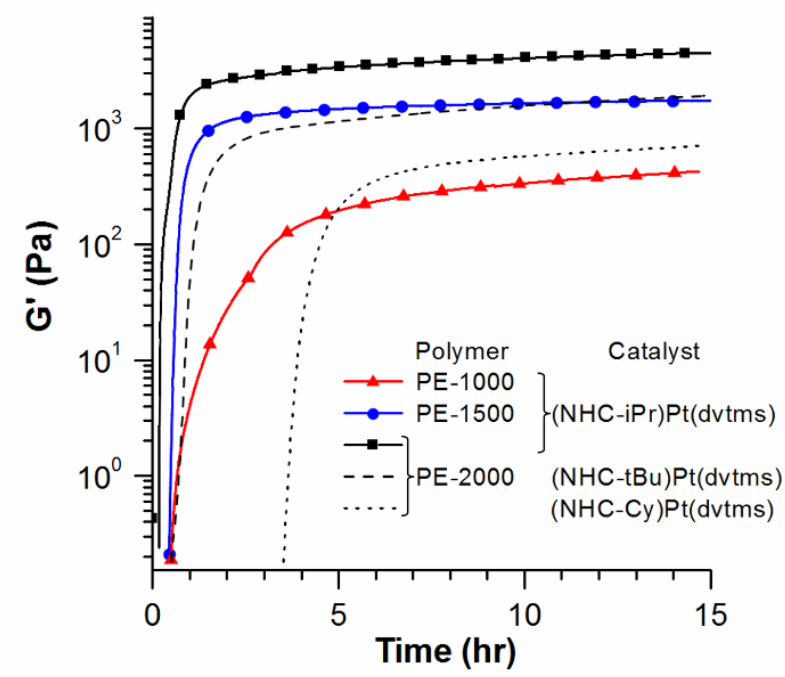

Figure 2. In-situ rheological monitoring of crosslinking between various PEdivin<yl and polyhydrosilane at $110^{\circ} \mathrm{C}(6 \mathrm{wt} \%$ solution in CDD) and $300 \mathrm{ppm}$ of various Pt catalysts. For clarity only the storage moduli are represented enables to distinguish differences of isomerizations in dilute media with far greater sensitivity than NMR. (NHCiPr)Pt(dvtms) will be chosen for the remaining studies. The same trend between catalysts was found for PE-600, PE1000 and PE-1500 when using the same catalyst (NHCiPr)Pt(dvtms) (Figures 2 and S7, S8). The moduli after 15 hours are dramatically increasing with the molecular weights (e.g. ranging from $430 \mathrm{~Pa}$ for PE-1000 to $4.5 \mathrm{kPa}$ for PE2000). Although one might expect at first glance higher crosslinking densities for shorter PE segments, after measuring the intrinsic viscosity with SEC and estimating the critical overlap concentration for each $\operatorname{PE~}\left(\varphi^{*}\right.$, Table 1$)$, it appears that at $6 \mathrm{wt} \%$ all solutions are below the critical overlap concentration, and all the more so when molecular weights are decreasing. In such conditions, the final crosslinking density is indeed expected to be strongly reduced for lower molecular weights. ${ }^{[24]}$

\section{Aerogel synthesis by solvent crystallization and sublimation}

As an alternative drying process to $s-\mathrm{CO}_{2}$ extraction, which typically requires high pressures (> 150 bar) to ensure miscibility of liquid- $\mathrm{CO}_{2}$ and apolar solvents ${ }^{[27]}$ and that must be carefully controlled to avoid cracks, ${ }^{[7]}$ we chose to carry out gelations in a crystallizable solvent, cyclododecane (CDD, $\mathrm{T}_{\mathrm{m}}=61^{\circ} \mathrm{C}, \mathrm{T}_{\mathrm{b}}=244^{\circ} \mathrm{C}$ ) which is an excellent solvent for polyethylene at high temperatures, has a low vapor pressure when crystallized and is widely used in archaeology as a temporary consolidant. ${ }^{[28]}$ The frozen gels can be easily handled and cut at room temperature, while the CDD is straightforwardly extracted and recovered by sublimation 
under reduced pressure. The morphology of our polyethylene-based aerogels and their physical properties are thus expected to be strongly related to the respective crystallizations of polyethylene and CDD. We monitored therefore this crystallization by combination of DSC and rheology, by applying a slow cooling ramp $\left(0.7^{\circ} \mathrm{C} \cdot \mathrm{min}^{-1}\right)$, after complete gelation between PE-divinyl and polyhydroxysilane (47 mg cm$~_{-3}$ in CDD) at $110^{\circ} \mathrm{C}$ during 15 hours (Figure 3 ). Upon cooling, the PE-1000 and PE-2000 networks display a unique crystallization event starting around $58^{\circ} \mathrm{C}$, illustrated by a sharp exotherm in DSC and a dramatic increase of the storage modulus. Upon subsequent heating, the PE-1000 network displays a first melting event at $61^{\circ} \mathrm{C}$, consistent with the melting of CDD, and a second event at $63^{\circ} \mathrm{C}$ that we attribute to melting of PE segments. The storage modulus is more sensitive to the melting transitions than enthalpy change in DSC analysis, and shows a continuous decrease up to $70^{\circ} \mathrm{C}$, when the modulus of the amorphous gel is recovered. The PE-2000 network displays a much more pronounced crystallization of PE segments, characterized by an elastic plateau above the melting of CDD, of about 50-100

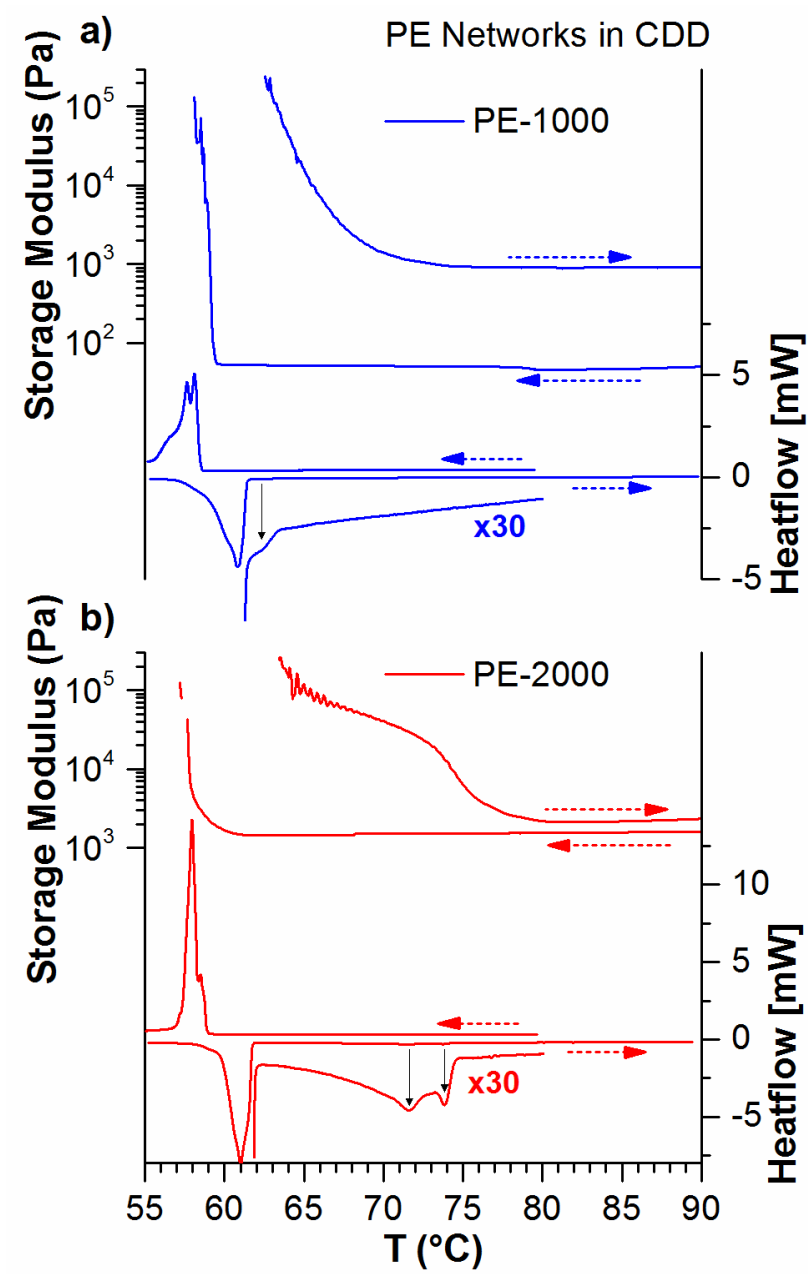

Figure 4. Crystallization monitoring of PE network in CDD for PE-1000 (a) and PE-2000 (b) by combination of rheology (top part) and DSC (bottom part). The arrows indicate the cooling and heating cycles. Insets display expanded parts of the DSC heating curve.
$\mathrm{kPa}$, and a melting of $\mathrm{PE}$ segments above $70^{\circ} \mathrm{C}$. In contrast, a semi-diluted and entangled UHMWPE solution at $110^{\circ} \mathrm{C}$ (Figure S9) shows distinct crystallization for PE and CDD at $86^{\circ} \mathrm{C}$ and $59^{\circ} \mathrm{C}$, respectively.

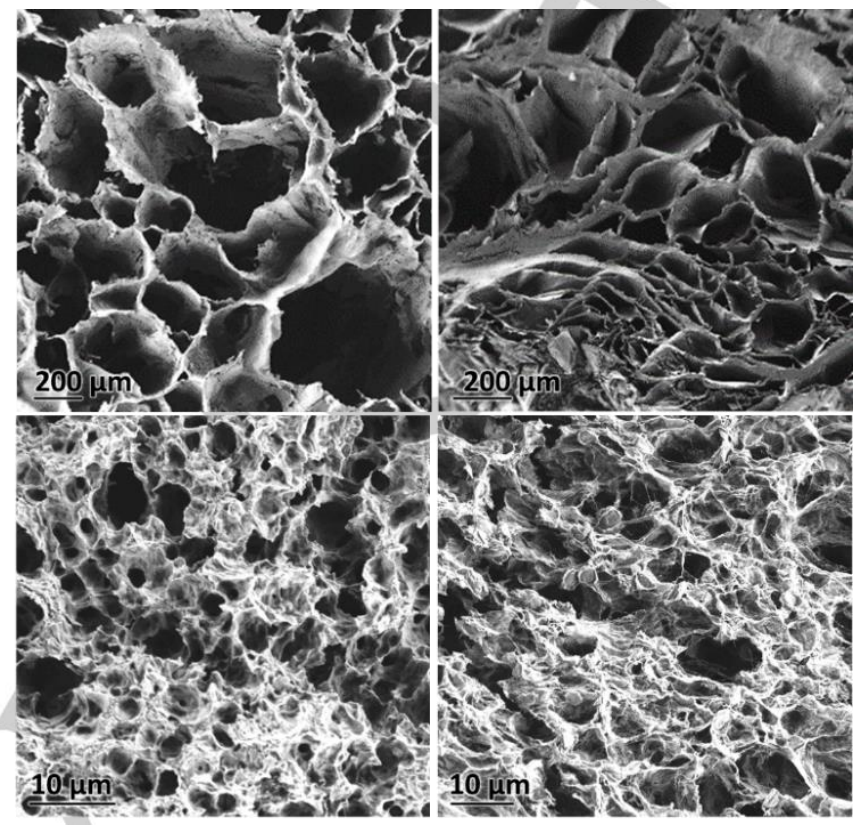

Figure 3. . SEM micrographs of fully evacuated aerogels obtained from PE-1000 (left) and PE-2000 (right) after quenching the gels from $110^{\circ} \mathrm{C}$ to $0^{\circ} \mathrm{C}$ (top) and after slow cooling at $2^{\circ} \mathrm{C} . \mathrm{h}-1$ (bottom).

It appears thus that the structure of PE chemical networks is primarily driven by the crystallization of CDD, which is progressively expelled from the PE gels as the crystalline domains grow. The concomitant increase of polymer concentration in the gel eventually induces crystallization of the polyethylene segments and complete phase separation between the polymer and the crystalline solvent. Upon subsequent heating above the melting temperature of CDD, PE crystalline segments of PE-1000 network dissolve readily in liquid CDD whereas PE-2000 network remains semicrystalline at higher temperatures.

As the crystallization rate of CDD appears critical in our systems, we compared PE-1000 and PE-2000 aerogels obtained by quenching the gels from $110^{\circ} \mathrm{C}$ to an ice bath, with gels slowly cooled from $63^{\circ} \mathrm{C}$ to $59^{\circ} \mathrm{C}$ at about $2^{\circ} \mathrm{C} \mathrm{h}$. The CDD of all samples was fully extracted in vacuum at $40^{\circ} \mathrm{C}$ to yield monolithic materials before observing the morphology with SEM (Figure 4). Whereas quenching leads to the formation of very large CDD crystallites, and thus pores about 200-300 $\mu \mathrm{m}$ wide, slow cooling leads to the formation of much smaller pores, with macropores of about 5-10 $\mu \mathrm{m}$ and even submicronic pores. The very different pore sizes in the two cases are most probably governed by the difference in crystallization rate of CDD, ${ }^{[29]}$ which is fast in the case of a super-cooled isothermal crystallization in the first case, and much slower when a large temperature gradient is taking place throughout the sample in the second case. For comparison, UHMWPE-based aerogels show thin lamellae 
of about $10 \mu \mathrm{m}$ large, loosely bound by PE filaments (Figure S10). To complete the investigation on porosity, nitrogen sorption porosimetry was performed on the aerogels (Figure 5). While the relatively low values of adsorbed volumes and their steep increase near $\mathrm{P} / \mathrm{P}_{0}=1$ indicate that the aerogels are mostly macroporous (pore sizes $>100 \mathrm{~nm}$ ), the BET specific surface area $\left(\mathrm{S}_{\mathrm{BET}}\right)$ for slowly crystallized samples increases from $18 \mathrm{~m}^{2} \mathrm{~g}^{-1}$ for PE-1000 to $38 \mathrm{~m}^{2} \mathrm{~g}^{-1}$ for PE2000. As discussed above, we believe this to be due to the two-steps crystallization mode evidenced in PE-2000 aerogels: independent crystallization of PE segments before formation of CDD crystallites might favour the formation of smaller pores. In the case of quenched crystallization, $S_{B E T}$ only varies from 16 to $22 \mathrm{~m}^{2} \mathrm{~g}^{-1}$ for PE-1000 and PE-2000.

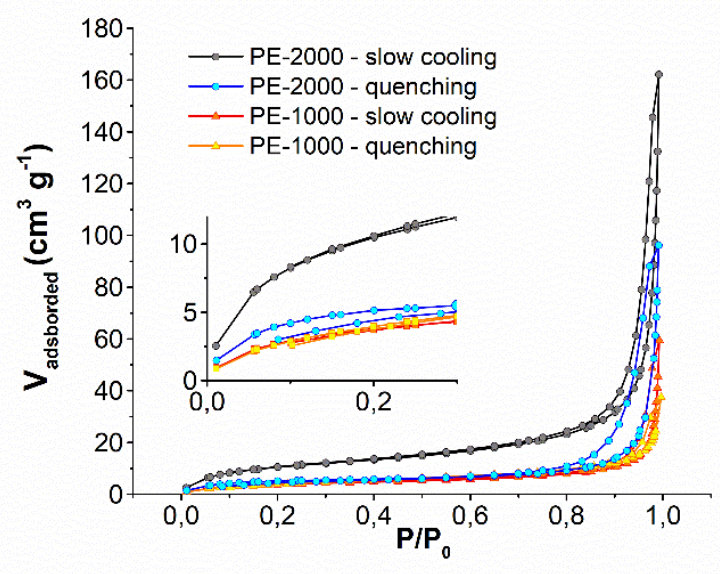

Figure 5. Nitrogen sorption isotherms of aerogels synthesized from PE-1000 and PE-2000 and recrystallized at $2^{\circ} \mathrm{C} \mathrm{h}^{-1}$ (slow crystallization) or quenched from $110^{\circ} \mathrm{C}$ to $0^{\circ} \mathrm{C}$. The inset shows the adsorption and desorption curves at low $\mathrm{P} / \mathrm{P}_{0}$ ratios.

Starting from an initial polymer concentration about $47 \mathrm{mg}$ $\mathrm{cm}^{-3}$ in the gels, the apparent densities of the final aerogels after sublimation ( $d_{\text {aerogel}}$, Table 1 ) indicate that the shrinkage is significant in the case of UHMWPE and PE-2000, but strongly reduced for shorter PE segments. We believe the shrinkage to be caused by the crystallization of PE segments occurring in liquid gels. In the case of shorter PE segments, the crystallization of polyethylene essentially occurs in already frozen gels and does not induce shrinking of the gel.

\section{Physical and shape memory properties of PE aerogels}

The thermal and mechanical properties of polyethylenebased aerogels were measured by DSC and compression tests, respectively ( $\mathrm{X}_{\text {aerogel }}, \mathrm{E}_{\text {aerogel }}$ and $\mathrm{T}_{\mathrm{m}}$, Table 1 and Figures S11, S12). Our design strategy based on crosslinking of well-defined PE-segments lead indeed to networks with high crystallinities ranging from 36 to $43 \%$, and narrow melting temperatures from 60 to $110^{\circ} \mathrm{C}$ directly related to the length of PE segments. Following the analysis of Ashby-Gibson, ${ }^{[30]}$ the compression moduli of the aerogels $E$ are expected to vary as $\left(d_{\text {aerogel }} / d_{\text {bulk-PE }}\right)^{2}$, i.e. to strongly increase with the apparent density. Whereas aerogels made from well-defined PE segments behave in relatively good accordance with this theory, the aerogel from UHMWPE shows comparatively a very low compression modulus, about 30 times lower than PE-2000 aerogel at comparable density (Figure S13). Even more importantly for applications requiring dimensional stability, while UHMWPE shows extremely low resilience at room temperature, with barely $11 \%$ recoverable deformation after a $50 \%$ compression step, chemically crosslinked PE aerogels PE-2000, PE-1500 and PE-1000 demonstrate excellent mechanical resilience, with nearly $100 \%$ recoverable deformation and fully superimposable loading cycles $\left(\mathrm{E}_{\mathrm{sp}}\right.$, Table 1 and Figure $\mathrm{S} 12)$. The mechanical stability demonstrated by chemically crosslinked aerogels prompted us to study further their behavior as shape-memory materials. The combination of high crystallinity with narrow melting transition and dense covalent crosslinking is effectively ideal to reversibly lock-in various shapes. ${ }^{[11]}$ After heating the PE-2000 aerogel at $125^{\circ} \mathrm{C}$, i.e. at a temperature where the aerogels are only maintained by chemical crosslinks (See Figure S14 for compression tests at $125^{\circ} \mathrm{C}$ ), a $50 \%$ compression strain is applied, and maintained while cooling down the sample to room temperature. This new shape is locked-in by crystallization of PE segments, and maintained even after release of the stress. Upon heating back the sample to $125^{\circ} \mathrm{C}$, the sample recovers its initial shape.

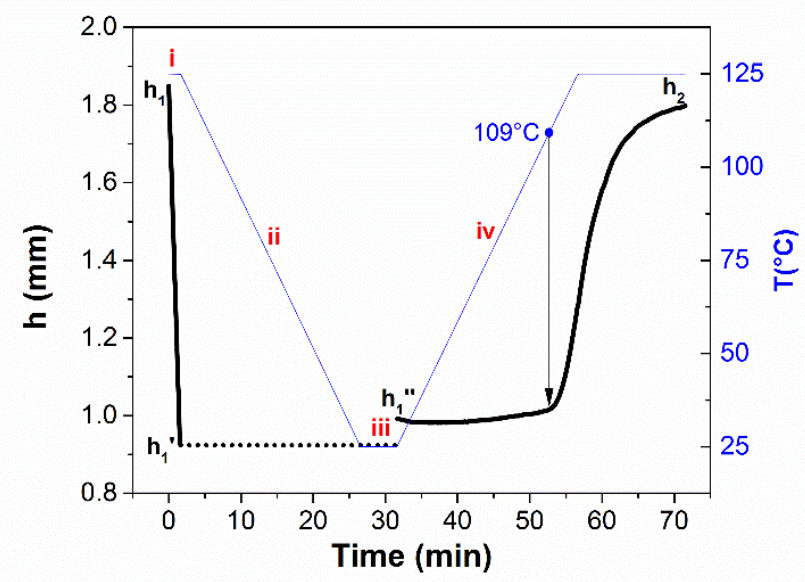

Figure 6. Analysis of shape-memory performance in PE-2000 aerogel. i) $50 \%$ compression step at $125^{\circ} \mathrm{C}$, ii) cooling step at $3^{\circ} \mathrm{C} \mathrm{min}^{-1}$ while maintaining the compression, iii) release of stress, iv) heating at $3^{\circ} \mathrm{C} \mathrm{min}^{-1}$

Quantitative analysis of these shape-memory properties was realized by three successive cycles while measuring the shape fixity ratios $\left(R_{f}\right)$ at $25^{\circ} \mathrm{C}$ and the shape recovery ratio $\left(R_{r}\right)$ upon heating back the samples to $125^{\circ} \mathrm{C}$ (See Figure 6 and details in Supplementary Information). The PE-2000 aerogel was characterized by $R_{f}$ ratios of $1,0.96$ and 0.96 , and $R_{r}$ ratios of $0.95,0.96$ and 0.95 for the three successive cycles. This evidences an excellent fixation of shape thanks to the high crystallinity of PE-2000 samples as well as a 
remarkable shape recovery driven by the dense, chemically crosslinked network present in the porous material.

It is interesting to note that while the shape recovery starts at $109^{\circ} \mathrm{C}$, i.e. at the melting point of PE-2000 as determined by DSC (See Figure S11), complete shape recovery is significantly delayed and continues for almost 15 min when $125^{\circ} \mathrm{C}$ is reached. As a consequence the calculation of the fill factor commonly used to characterize fast-recovery shape memory materials ${ }^{[31 b, 32]}$ only gives a poor result of $f_{m} \approx 0.10$ between 109 and $125^{\circ} \mathrm{C}$ (See Figure S15). We believe that this slow recovery is essentially due to the fast heating ramp used $\left(3^{\circ} \mathrm{C} \cdot \mathrm{min}^{-1}\right)$ and a low thermal conductivity in our porous material, the latter being a very interesting property that will be further studied in a forthcoming publication. Both effect contribute to generate high thermal gradients within the sample and strongly delayed temperature increase at its core. As reported recently by Leventis and coworkers, ${ }^{[32]}$ the relatively low Young modulus of the sample above the melting transition $(50 \mathrm{kPa})$ might also contribute to slow recoveries.

\section{Conclusion}

We reported here that adding chemical crosslinking in aerogels of polyethylene enables obtaining materials with far superior mechanical properties than aerogels that are only maintained with physical crosslinks and consequently afford novel applications as shape-memory materials. While we expect that these results could be generalized to other semicrystalline polymer-based networks, we emphasize that the crosslinking strategy is of utmost importance to ensure efficient gelation in dilute media while also maintaining a high crystallinity in the final material. The use of well-defined and highly crystalline $\alpha, \omega$-divinyl-polyethylenes was essential in our case to obtain polymer networks with precise segment lengths.

The high mechanical resilience of these PE aerogels, associated to the inherent hydrophoby and chemical stability of HDPE prefigures that high performance hybrid aerogels could be obtained by combining sol-gel chemistry and highly crystalline PE networks.

\section{Experimental Section}

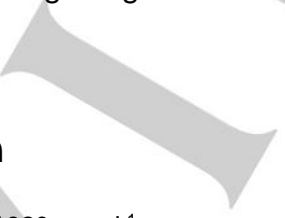

Aerogel obtained with $M_{\mathrm{n}}(\mathrm{PE})=1920 \mathrm{~g} \mathrm{~mol}^{-1}$.

A $10 \mathrm{~mL}$ vial was charged with $\alpha, \omega$-divinyl-polyethylene $(0.30 \mathrm{~g}, 0.31 \mathrm{mmol}$ of vinyl groups), cyclododecane (CDD, $5.4 \mathrm{~g}, 94 \mathrm{wt} \%$ ) and the crosslinker polymethylhydrosilane $\left(\mathrm{PMHS}\right.$, [SiH] PMHS $^{2} 0.011 \mathrm{~mol} \mathrm{~g}^{-1}, 0.056 \mathrm{~g}, 0.62$ $\mathrm{mmol}$,). The vial was placed in a dry heating bath at $110^{\circ} \mathrm{C}$ during 1 hour in order to solubilize all the reactants. Then, a solution of catalyst in CDD $\left(0.158 \mathrm{~g}, 300 \mathrm{ppm}\right.$ according to vinyl group, $9.3710^{-2} \mu \mathrm{mol}$ ) was added in the vial, and mixed during 10 seconds in a vortex mixer. To avoid the crystallization of the solvent, the vial was rapidly placed on the heating bath at $110^{\circ} \mathrm{C}$ in order to start the crosslinking reaction. The gelation was performed during 15 hours. Then, the crystallization step was performed following two ways. The gel was either quenched directly with an ice bath or slowly cooled from $63^{\circ} \mathrm{C}$ to $59^{\circ} \mathrm{C}$ at about $2^{\circ} \mathrm{C} \mathrm{h}^{-1}$. After crystallization, the frozen gel was then recovered by breaking the glass vial and the solvent was then fully extracted under vacuum at $40^{\circ} \mathrm{C}$. The completion of solvent extraction was monitored by gravimetric analysis.

\section{Acknowledgements}

We thank Pierre-Yves Dugas for his help with SEM analysis, ANR (grant AEROLEFIN, ANR-17-CE07-0006) for financial support, the technical center for microstructures of Lyon $(\mathrm{CT} \mu)$ and the Lyon Polymer Science and Engineering SEC characterization platform. We thank Sylvain Deville for stimulating discussions on ice templating.

Keywords: aerogels $\cdot$ crystallization templating $\cdot$ mesoporous materials $\cdot$ polymers $\cdot$ shape-memory

[1] a) A. C. Pierre, G. M. Pajonk, Chem. Rev. 2002, 102, 4243. b) C. J. Brinker, C. J. Brinker, G. W. Scherer, S. G. W, Sol-Gel Science: The Physics and Chemistry of Sol-Gel Processing, Elsevier Science, 1990.

[2] G. M. Pajonk, E. Elaloui, P. Achard, B. Chevalier, J.-L. Chevalier, M. Durant, J. Non-Cryst. Solids 1995, 186, 1.

[3] G. Zu, J. Shen, L. Zou, W. Wang, Y. Lian, Z. Zhang, A. Du, Chem. mater. 2013, 25, 4757 .

[4] M. A. Worsley, T. Y. Olson, J. R. Lee, T. M. Willey, M. H. Nielsen, S. K. Roberts, P. J. Pauzauskie, J. Biener, J. H. Satcher Jr, T. F. Baumann, J. Phys. Chem. Letters 2011, 2, 921.

[5] a) A. Rigacci, J. Marechal, M. Repoux, M. Moreno, P. Achard, J. NonCryst. Solids 2004, 350, 372. b) A. Bang, C. Buback, C. SotiriouLeventis, N. Leventis, Chem. Mater. 2014, 26, 6979.

[6] J. W. Steed, Chem. Commun. 2011, 47, 1379.

[7] T. Woignier, J. Phalippou, F. Despetis, S. Calas-Etienne, in Handbook of Sol-Gel Science and Technology: Processing, Characterization and Applications (Ed.: Klein, Lisa and Aparicio, Mario and Jitianu, Andrei), Springer International Publishing, Cham, 2018, pp. 985-1011.

[8] H. Gesser, P. Goswami, Chem. Rev. 1989, 89, 765.

[9] S. A. Al-Muhtaseb, J. A. Ritter, Adv. Mater. 2003, 15, 101

[10] a) N. Diascorn, S. Calas, H. Sallée, P. Achard, A. Rigacci, J. Supercrit. Fluids 2015, 106, 76. b) S. Donthula, C.Mandal, T. Leventis, J. Schisler, A.M. Saeed, C. Sotiriou-Leventis, N. Leventis, Chem. Mater. 2017, 29, 4461-4477.

[11] a) Z. Wang, Z. Dai, J. Wu, N. Zhao, J. Xu, Adv. Mater. 2013, 25, 4494. b) L. Jiang, K. Kato, K. Mayumi, H. Yokoyama, K. Ito, ACS Macro Letters 2017, 6, 281. c) L. Druel, R. Bardl, W. Vorwerg, T. Budtova, Biomacromolecules 2017, 18, 4232. d) S. Salomo, T. X. Nguyen, D. K. Le, X. Zhang, N. Phan-Thien, H. M. Duong, Colloids Surf. A, 2018, 556, 37. e) S. Zhao, W. J. Malfait, A. Demilecamps, Y. Zhang, S. Brunner, L. Huber, P. Tingaut, A. Rigacci, T. Budtova, M. M. Koebel Angew.Chem.Int. Ed. 2015, 54, 14282.

[12] C. Rudaz, R. Courson, L. Bonnet, S. Calas-Etienne, H. Sallée, T. Budtova, Biomacromolecules 2014, 15, 2188

[13] S. S. Silva, A. R. C. Duarte, J. F. Mano, R. L. Reis, Green Chem. 2013, 15, 3252.

[14] C. A. García-González, M. Alnaief, I. Smirnova, Carbohydr. Polym. 2011, 86, 1425.

[15] Z. Zhang, G. Sèbe, D. Rentsch, T. Zimmermann, P. Tingaut, Chem. Mater. 2014, 26, 2659.

[16] a) C. Daniel, D. Alfano, V. Venditto, S. Cardea, E. Reverchon, D. Larobina, G. Mensitieri, G. Guerra, Adv. mater. 2005, 17, 1515. b) C. Daniel, S. Longo, R. Ricciardi, E. Reverchon, G. Guerra, Macromol. Rapid Commun. 2013, 34, 1194. c) C. Daniel, J. G. Vitillo, G. Fasano, G. Guerra, ACS Appl. Mater. Interfaces 2011, 3, 969.

[17] a) Y. Zhang, D. Rodrigue, A.K. Abdellatif, J. Appl. Polym. Sci. 2003 90, 2111-2119. b) Z. Xing, G. Wu, S. Huang, S. Chen, H. Zeng, J. Supercrit. Fluids, 2008, 47, 281-289

[18] a) W. Lu, Z. Yuan, Y. Zhao, H. Zhang, H. Zhang, X. Li, Chem. Soc. Rev., 2017, 46, 2199-2236 b) P. Arora, Z. Zhang, Chem. Rev., 2004, 104, 4419-4469 c) D. Ihm, J. Noh, J. Kim, J. Power Sources, 2002, 109, 388-393

[19] G. F. Müller, M. Stürzel, R. Mülhaupt, Adv. Funct. Mater. 2014, 24, 2860 . 
[20] C. Daniel, S. Longo, G. Guerra, Polyolefins Journal. 2015, 2(1), 4955.

[21] Q. Xing, R. Li, X. Zhang, X. Dong, D. Wang, L. Zhang, Colloid Polym. Sci. 2015, 293, 3573.

[22] a) J. Mazzolini, E. Espinosa, F. D’Agosto, C. Boisson, Polym. Chem. 2010, 1, 793. b) I. German, W. Kelhifi, S. Norsic, C. Boisson, F. D'Agosto, Angew. Chem. Int. Ed. 2013, 52, 3438.

[23] S. Norsic, C. Thomas, F. D'Agosto, C. Boisson, Angew. Chem. Int. Ed. 2015, 54, 4631.

[24] T. Sakai, T. Katashima, T. Matsushita, U. Chung, Polym. J. 2016, 48, 629.

[25] a) Y. Nakajima, S. Shimada, RSC Advances 2015, 5, 20603. b) A. Bouvet-Marchand, C. Chatard, A. Graillot, G. Boutevin, C. Loubat, D. Grosso, React. Chem. Eng. 2018, 3, 696.

[26] a) I. E. Markó, S. Stérin, O. Buisine, G. Mignani, P. Branlard, B. Tinant, J.-P. Declercq, Science 2002, 298, 204. b) I. E. Markó, S. Sterin, O. Buisine, G. Berthon, G. Michaud, B. Tinant, J.-P. Declercq, Adv. Synth. Catal. 2004, 346, 1429.

[27] W. Wu, J. Ke, M. Poliakoff, J. Chem. Eng. Data 2006, 51, 1398.

[28] I. Brückle, J. Thornton, K. Nichols, G. Strickler, J. Amer. Instit. Conserv. 1999, 38, 162

[29] W. Bald, J. microscopy 1986, 143, 89.

[30] a) L. J. Gibson, M. F. Ashby, Cellular Solids: Structure and Properties, Cambridge University Press, 1997. b) O. M. Istrate, B. Chen, Soft Matter 2011, 7, 1840

[31] a) T. Xie, Nature 2010, 464, 267. b) C. Liu, H. Qin, P. T. Mather, J. Mater. Chem. 2007, 17, 1543-1558. c) B. T. Michal, W. A. Brenn, B. N. Nguyen, L. S. McCorkle, M. A. B. Meador, S. J. Rowan, Chem. Mater. 2016, 28, 2341.

[32] a) S. Malakooti, S. Rostami, H.G. Churu, H. Luo, J. Clark, F. Casarez, O. Rettenmaier, S. Daryadel, M. Minary-Jolandan, C. SotiriouLeventis, N. Leventis, H. Lu, RSC Adv. 2018, 8, 21214-21223. b) S. Donthula, C. Mandal, J. Schisler, T. Leventis, M.A.B. Meador, C. Sotiriou-Leventis, N. Leventis, ACS Appl. Mater. Interfaces. 2018, 10, 23321-23334. 


\section{RESEARCH ARTICLE}

Polyethylene aerogels with low density and excellent mechanical resilience were obtained by combining and maximizing physical crosslinking, due to crystallization, and chemical crosslinking, controlled by hydrosilylation reactions. These materials display remarkable shamememory properties.

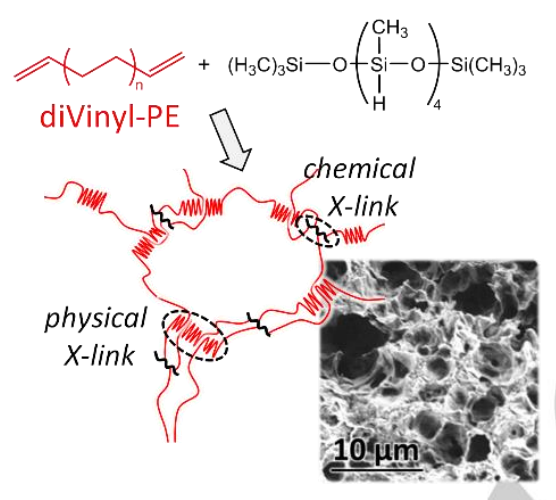

Douriya Khedaioui, Christophe

Boisson, Franck D'Agosto and Damien Montarnal*

Page No. - Page No.

Polyethylene aerogels combining physical and chemical crosslinking allow improved mechanical resilience and shape-memory properties 